\title{
Endoscopist's occupational dose evaluation related to correct wearing of dosimeter during $X$-ray-guided procedures
}

\section{다 (1) $(-)$}

\author{
Authors \\ Roberta Gerasia', Dario Ligresti², Fabio Cipolletta², Antonino Granata², Ilaria Tarantino², Luca Barresi², Michele \\ Amata $^{2}$, Sabrina Benenati ${ }^{1}$, Giuseppe Gallo ${ }^{1}$, Corrado Tafaro ${ }^{1}$, Roberto Miraglia ${ }^{1}$, Mario Traina ${ }^{2}$
}

Institutions

1 IRCCS-ISMETT (Istituto Mediterraneo per i Trapianti e Terapie ad alta specializzazione), Palermo, Italy Radiology Service, Department of Diagnostic and Therapeutic Services, Palermo, Italy

2 IRCCS-ISMETT (Istituto Mediterraneo per i Trapianti e Terapie ad alta specializzazione), Palermo, Italy Endoscopy Service, Department of Diagnostic and Therapeutic Services, Palermo, Italy

submitted 4.7.2018

accepted after revision 29.10.2018

Bibliography

DOI https://doi.org/10.1055/a-0841-3350 |

Endoscopy International Open 2019; 07: E367-E371

(c) Georg Thieme Verlag KG Stuttgart · New York

ISSN 2364-3722

Corresponding author

Dario Ligresti, Endoscopy Service, Department of Diagnostic and Therapeutic Services, IRCCS ISMETT UPMC, Via E. Tricomi 5, 90127 Palermo, Italy

Fax: +39-091-2192400

Phone: +390912192772

Phone: +393669142811 (mob.)

dligresti@ismett.edu

\section{ABSTRACT}

Background Since endoscopists performing procedures in the endoscopy suite can change their position by turning their back, side or front toward the X-ray source, this study aimed to establish whether dosimeter position affects the correct evaluation of an endoscopist's personal radiation exposure during $\mathrm{X}$-ray-guided procedures.

Materials and methods Between January and February 2018, two dosimeters specularly placed outside the lead apron (anterior one on the chest and posterior one on the back) measured endoscopists' personal dose equivalent (Hp) during $62 \mathrm{X}$-ray-guided procedures on adult and pediatric patients. Procedures were divided into three groups considering the position taken by the endoscopist with respect to the radiation source. For each group, the difference between mean $\mathrm{Hp}$ from the anterior and posterior dosimeters was calculated.

Results A statistically significant difference in mean $\mathrm{Hp}$ was recorded for the endoscopists' frontal and back positions ( $P=0.014$, and $P<0.00001$, respectively). No significant difference was found in mean $\mathrm{Hp}$ for the side position $(P=0.489)$.

Conclusions The position of personal dosimeters affects the correct evaluation of endoscopists' radiation exposure during X-ray-guided procedures when frontal and back positions were recorded. To correctly evaluate radiation doses, the whole-body dosimeter should be worn according to the position of the endoscopist with respect to the radiation source; otherwise, it results in an incorrect personal dose evaluation, which may lead to substantial underestimation of staff exposure.

\section{Introduction}

The estimated risk associated with exposure to ionizing radiation is based on evaluation of the effective dose (E), starting from the equivalent dose $(\mathrm{H})$ received during $\mathrm{X}$-ray-guided procedures. Concerning endoscopic procedures, risks have been widely studied, with special focus on the potential risk of radiation-induced cancer [1-9].
As fluoroscopy is fundamentally necessary in endoscopic retrograde cholangiopancreatography (ERCP) and any other interventional procedure (such as enteral stent placement, balloon dilatation of stenosis, advanced endoscopic ultrasound (EUS)-guided procedures, and radiation exposure), potential occupational hazards are inevitable for advanced endoscopists $[1,10]$.

Many aspects, including complexity of procedures, patient size (e.g. pediatric patients, obese patients), and experience 
of the operator, influence the annual effective doses received by the operators. In addition, the type of X-ray equipment used to perform endoscopy procedures, a correctly operated $\mathrm{C}$-arm, including patient-detector distance, and pulsed fluoroscopy, may affect staff radiation doses [11]. However, the use of bed-mounted or ceiling-mounted shields, lead aprons, thyroid shields, protective glasses, and a distance as far as possible from the radiation source are established methods for reducing staff exposure.

Endoscopists can work with radiation, and reduce the possibility of suffering radiation effects by following radioprotection recommendations, such as correctly using personnel monitoring devices to estimate radiation exposure. In fact, as strongly recommended by the International Commission on Radiological Protection (ICRP), it is essential that professionals wear dosimeters correctly because no dose to which an individual is exposed can be accurately estimated without having some type of individual monitoring during all times of exposure [12]. There are studies and recommendations with regard to the correct evaluation of occupational dose of interventional radiology staff using two dosimeters [12,13]. However, the design of these studies is based only on dosimeters positioned one under and the other over the lead apron. Problems with improper wearing of dosimeters may include not only registration of high doses, but also very low doses that may suggest misuse of the devices or failure to wear them properly [12].

It has been shown that the numerical values of the personal dose equivalent depend on the position of the dosimeter [14]. While wearing a standard lead apron and thyroid shield can give us some form of reassurance of radiation safety, some people may not worry about how the position of the personal dosimeter related to their own position with respect to the radiation source can affect the correct personal dose assessment.

Depending on the different types of procedure or the habits of the operator, endoscopists can change their position in the endoscopy suite by turning their back, side or front toward the $\mathrm{X}$-ray source. Thus, this study aimed to establish whether the position of personal dosimeters affects the correct evaluation of endoscopists' radiation exposure during X-ray-guided procedures.

\section{Materials and methods}

This study was approved by our institutional review board, which waived the need for consent for data collection. An informed consent specific to each procedure was obtained in all cases.

\section{Patient population}

Between January and February 2018, data from 62 consecutive $X$-ray-guided endoscopic procedures performed in a single tertiary care center were prospectively collected. The study population included patients with either biliopancreatic or upper/ lower gastrointestinal pathologies.

\section{X-ray equipment}

A flat-panel detector mobile C-arm (Cios Alpha, Siemens Healthineers, Erlangen, Germany), in our suites since 2017, was used to perform all procedures, with postero-anterior projection. A fluoroscopy trajectory pre-set by the manufacturer, a fluoroscopy pulse-rate fixed at 15 pulses/second, last image hold, and image loop functions were all routinely employed. During the study, a high frame rate, magnification, and oblique projections were only used at certain times during some procedures. The technique parameters, including tube kilovoltage $(\mathrm{kV})$ and tube current-time product $(\mathrm{mAs})$, were determined automatically by the automatic exposure control system.

This equipment does not allow any change in the source-todetector distance; however, the patient-to-detector distance was reduced as much as possible during every procedure.

In addition, patients were placed on a separate angiographic-bed system (Cmax Xray operating table, STERIS, Mentor, $\mathrm{OH}$, USA), with a bed-mounted shield $(0.5 \mathrm{~mm}$ lead equivalent) used during all of the procedures.

\section{Dose measurement}

All procedures were performed by endoscopists who always wore protective aprons with thyroid shields $(0.5 \mathrm{~mm}$ lead equivalent) and protective glasses with side protection (0.75 $\mathrm{mm}$ lead equivalent).

Electronic dosimeters have been proven to be effective for studies of radiation exposure [12]. In our study, we used two electronic personal dosimeters (EPD MK2.3, Thermo Fisher Scientific, Benham, UK), able to respond to photon energies down to $15 \mathrm{keV}$, with an angular response of $\pm 20 \%$ up to $\pm 75^{\circ}$, and an accuracy of $\pm 10 \%$, calibrated to measure the personal dose equivalent at $10 \mathrm{~mm}$ depth $[\mathrm{Hp}(10)]$. These dosimeters have a valid calibration and quality control certificate according to ISO/IEC guide 98 and to EA-4/02 standards requirements, updated every year.

The two dosimeters were placed with one outside the lead apron at the left upper chest position of the endoscopist, and the other at the back, specular to the first ( $\triangleright$ Fig. 1).

$\mathrm{Hp}(10)$ (in units of $\mu \mathrm{Sv}$ ) measured by the two dosimeters was manually recorded, along with the dose area product (DAP) and fluoroscopy time (FT), after each procedure. The working position of the endoscopist with respect to the radiation source was also registered.

In order to differentiate $\mathrm{Hp}$ from the two dosimeters (anterior and posterior), $\mathrm{Hp}$ values were named, $\mathrm{Hp}(10)$-ANT and $\mathrm{Hp}$ (10)-POST, respectively.

\section{Statistical analysis}

According to the working position of the endoscopist, procedures were divided into three groups: frontal position, back position, and side or mixed position.

Operators' Hp, patients' DAP, and FT-related data were analyzed for every single procedure, and are expressed as mean value \pm standard deviation (SD), median, and range.

The differences between mean $\mathrm{Hp}(10)$-ANT and mean $\mathrm{Hp}$ (10)-POST of each group were also calculated using two-tailed 


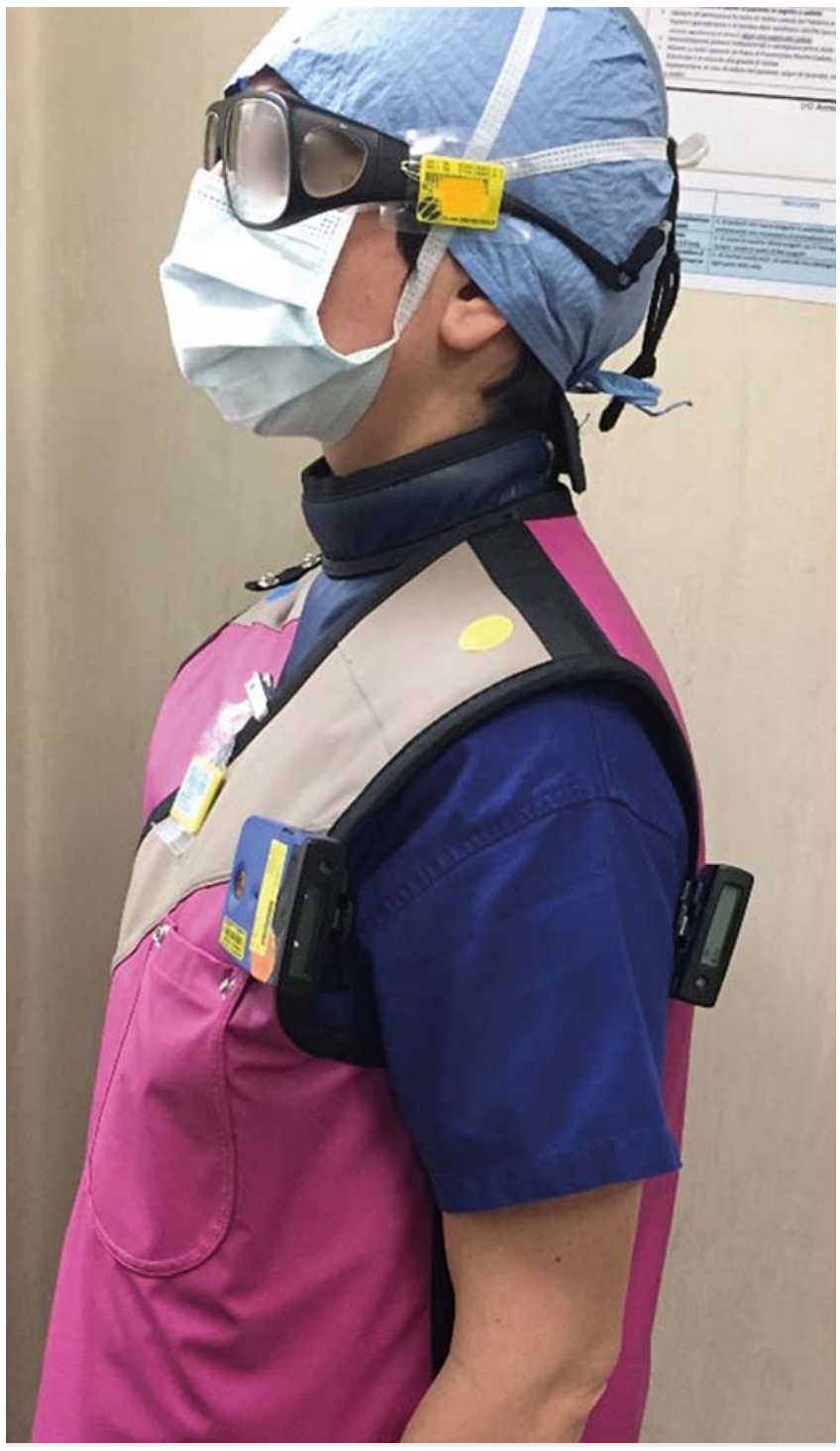

- Fig. 1 The two dosimeters were placed with one outside the lead apron at the left upper chest position of the endoscopist, and the other at the back, specular to the first.

Student's $t$ tests, with statistical results considered significant at $P$ values less than 0.05 .

\section{Results}

A total of 62 endoscopic X-ray-guided procedures were performed in 59 adult and 3 pediatric patients by 6 endoscopists. The procedures were as follows: 42 ERCP; 5 esophageal stricture dilatation ( 2 with and 3 without stenting); 4 colonic dilatation; 4 enteroscopy; 3 colonic stent placement; 1 rectovaginal fistula closure; 3 esophageal stent removal.

According to the working position of the endoscopist, 17 procedures were performed in the frontal position, 31 in the back position, and 14 in the side or mixed position. - Table 1 summarizes the type and number of procedures included in the study.
- Table 2 summarizes mean Hp(10)-ANT and mean Hp(10)POST, SD, median and range values (given in $\mu \mathrm{Sv}$ ), and the $t$ test results obtained from comparison of mean $\mathrm{Hp}(10)$-ANT and mean $\mathrm{Hp}(10)$-POST of each group. As shown, Hp(10)-ANT $\mu \mathrm{Sv}$ and $\mathrm{Hp}(10)$-POST $\mu \mathrm{Sv}$ were higher when the endoscopist assumed frontal and back positions (11.8 and $32.3 \mu \mathrm{Sv}$, respectively) ( $\triangleright$ Fig. 2 ). The results of the $t$ tests showed that there was a statistically significant difference in the means for the endoscopists' frontal position $(P=0.014)$ and for the endoscopists' back position $(P<0.00001)$. However, there was no statistically significant difference between means for the endoscopists' side/mixed position $(P=0.31)$.

$\mathrm{Hp}$ received during $\mathrm{X}$-ray-guided procedures are shown in - Table 3. In the frontal position, the posterior dosimeter measured $4.45 \%$ of the total $\mathrm{H}$ received by the endoscopist ( $\triangleright$ Table 3). In back and side/mixed positions, the posterior dosimeter measured the majority of the total $\mathrm{H}$ received by the endoscopist ( $96.16 \%$ and $63.50 \%$, respectively).

\section{Discussion}

Many studies are available on risks concerning endoscopic Xray-guided procedures, focusing especially on the potential risks of radiation exposure.

It has been proven that variations of occupational doses are related to the positioning of the operators within the working suite in relation to the $X$-ray equipment $[15,16]$. In addition, incorrect wearing of dosimeters may result in detection of excessively high doses, but also in registration of very low doses. In fact, both of these cases may indicate a misuse of dosimeter wearing [12].

A significant difference in $\mathrm{Hp}(10)$ between anterior and posterior dosimeter was registered in this study, particularly when frontal and back positions were required. This means that when the procedure requires the endoscopist to take a frontal or back position, the whole-body personal dosimeter should be worn on the chest or back, respectively, for correct monitoring of personal dose. Moreover, in consideration of the statistically non-significant difference of $\mathrm{Hp}$ when the endoscopist takes a lateral/mixed position, only a side dosimeter would probably be sufficient for correct evaluation of the dose to the endoscopist.

The position of a personal whole-body dosimeter is usually on the torso at waist or chest level [10]. Our data demonstrate that if a whole body dosimeter is worn without taking into consideration the operator's position within the suite in relation to the radiation source, the operator's dose monitoring will be inaccurate, or even incorrect. Data measured by a posterior dosimeter correspond to the $\mathrm{H}$ not monitored if only using the anterior placement of the whole-body personal dosimeter. The $\mathrm{H}$ not monitored is: $4.45 \%$ for endoscopist's frontal position; $96.16 \%$ for the back position, and $63.50 \%$ for the side/mixed position. This results in a greater potential risk of fatal cancer to endoscopists due to radiation exposure, especially when the back position is taken.

The possibility of using two dosimeters, one worn on the chest and the other on the back, should be considered for ef- 
- Table 1 Type and number of procedures included in the study. The table shows the number of procedures according to endoscopist's working position.

\begin{tabular}{|l|c|c|c|c|}
\hline Procedure name & No. of procedures/endoscopist's position & Side/mixed \\
\hline & Front & Back & 28 & 7 \\
\hline ERCP & 7 & 2 & 1 & 42 \\
\hline Esophageal stricture dilatation & 2 & 1 & 1 & 5 \\
\hline Colonic dilatation & 2 & 0 & 4 & 4 \\
\hline Enteroscopies & 0 & 0 & 1 & 4 \\
\hline Colonic stent placement & 2 & 0 & 0 & 3 \\
\hline Rectovaginal fistula closure & 1 & 0 & 0 \\
\hline Esophageal stent removal & 3 & 31 & 14 \\
\hline Total & 17 & & 1 \\
\hline ERCP, endoscopic retrograde cholangiopancreatography. & & 3 \\
\hline
\end{tabular}

- Table 2 Equivalent doses $(\mathrm{H})$ at a depth of $10 \mathrm{~mm}$ of tissue $[(\mathrm{Hp}(10)]$ measured by the dosimeter placed outside the lead apron at the left upper chest position of the endoscopist [Hp(10)-ANT], and by the dosimeter at the back [ $\mathrm{Hp}(10)$-POST].

\begin{tabular}{|c|c|c|c|c|c|}
\hline \multirow[t]{2}{*}{ Endoscopist's position } & \multicolumn{2}{|c|}{ Hp(10)-ANT, $\mu \mathrm{Sv}$} & \multicolumn{2}{|c|}{ Hp(10)-POST, $\mu \mathrm{Sv}$} & \multirow[t]{2}{*}{$P$ value } \\
\hline & Mean (SD) & Median; Range & Mean (SD) & Median; Range & \\
\hline Frontal & $11.8(13.9)$ & $8 ; 0-39$ & $0.5(0.9)$ & $0 ; 0-3$ & 0.014 \\
\hline Back & $1.3(2.0)$ & $1 ; 0-7$ & $32.3(33.2)$ & $24 ; 3-130$ & $<0.00001$ \\
\hline Side/mixed & $13.5(12.4)$ & $10 ; 0-40$ & $23.5(28.2)$ & $12.5 ; 0-83$ & 0.31 \\
\hline
\end{tabular}

\section{Comparison between $\mathrm{Hp}(10)$ means \\ 40}

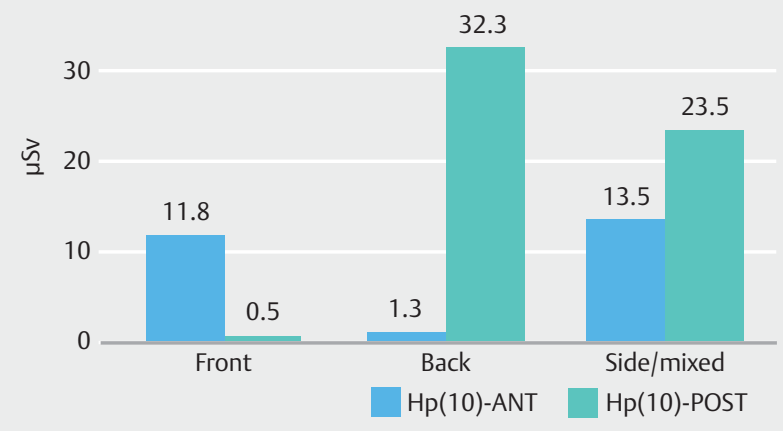

- Fig. 2 Comparison between mean Hp(10)-ANT and Hp(10)-POST for front, back and side/mixed positions.

fective monitoring of endoscopists' occupational dose. In addition, adequate educational programs for endoscopists could be helpful in avoiding misuse of radiation protection protocols.

Some limitations of this study should be considered. First, unlike hepatobiliary procedures performed by radiologists, for which the occupational dose is related to the type of procedure
- Table 3 Hp received during X-ray guided procedures monitored by the anterior and posterior dosimeter.

\begin{tabular}{|l|r|r|r|r|}
\hline Endoscopist's position & \multicolumn{2}{|c|}{ Hp(10)-ANT } & \multicolumn{2}{|c|}{ Hp(10)-POST } \\
\hline & Mean & $\%$ & Mean & \multicolumn{1}{c|}{$\%$} \\
\hline Frontal & 11.82 & 95.55 & 0.55 & 4.45 \\
\hline Back & 1.29 & 3.84 & 32.32 & 96.16 \\
\hline Side/mixed & 13.5 & 36.50 & 23.5 & 63.50 \\
\hline
\end{tabular}

being performed [16], the position taken by endoscopists likely does not depend on the kind of procedure, but may depend on their own behavior or approach to each procedure and patient. However, we need a greater number of procedures and operators to confirm this hypothesis. Second, pediatric procedures should be considered separately due to the lack of a sufficient number of procedures, and the difference in the patients' size, which could influence the results.

Future assessments with regard to dose evaluation of a larger number of endoscopists performing a single type of procedure and a pediatric population are needed. 
This study found that the position of personal dosimeters significantly affects the correct evaluation of endoscopists' radiation exposure during $X$-ray-guided procedures when frontal and back positions are taken. On the basis of these results, the whole-body personal dosimeter should be worn according to the position of the operator within the suite in relation to the radiation source. If this does not occur, it may result in a substantial underestimation of personal exposure. The possibility of using two dosimeters, one worn on the chest and the other on the back, should be considered for correct monitoring of endoscopists' occupational dose.

\section{Competing interests}

None

\section{References}

[1] Mekaroonkamol P, Keilin S. Editorial: ERCP-related radiation cataractogenesis: Is it time to be concerned? Am J Gastroenterol 2017; 112: $722-724$

[2] Staniszewska MA, Kujawski K, Kopeć R et al. ERCP procedures as a source of radiation risk to a single gastroenterologist. Med $\operatorname{Pr} 2017$; 68: $735-741$

[3] Seo D, Kim KH, Kim JS et al. Evaluation of radiation doses in patient and medical staff during endoscopic retrograde cholangiopancreatography procedures. Radiat Prot Dosim 2016; 168: 516-522

[4] Cohen RV, Aldred MA, Paes WS et al. How safe is ERCP to the endoscopist? Surg Endosc 1997; 11: 615-617

[5] Minami T, Sasaki T, Serikawa M et al. Occupational radiation exposure during endoscopic retrograde cholangiopancreatography and usefulness of radiation protective curtains. Gastroenterol Res Pract 2014; 2014: 926876

[6] Tsapaki V, Paraskeva KD, Mathou $\mathrm{N}$ et al. Patient and endoscopist radiation doses during ERCP procedures. Radiat Prot Dosim 2011; 147: $111-113$

[7] Buls N, Pages ], Mana F et al. Patient and staff exposure during endoscopic retrograde cholangiopancreatography. Br J Radiol 2002; 75: $435-443$
[8] Naidu LS, Singhal S, Preece DE et al. Radiation exposure to personnel performing endoscopic retrograde cholangiopancreatography. Postgrad Med J 2005; 81: 660-662

[9] Sulieman A, Paroutoglou G, Kapsoritakis A et al. Reduction of radiation doses to patients and staff during endoscopic retrograde cholangiopancreatography. Saudi J Gastroenterol 2011; 17: 23-29

[10] World Gastroenterology Organization Practice Guideline: Radiation Protection in the Endoscopy Suite. Introduction: Minimizing radiation exposure for patients and staff in endoscopy: a joint ASGE/IAEA/WGO Guideline. 2009 [Available at: http://www.worldgastroenterology. org/guidelines/global-guidelines/radiation-protection-in-the-endoscopy-suite]

[11] Tsapaki V, Paraskeva KD, Tsalafoutas IA et al. The impact of x-ray unit type used for endoscopic retrograde cholangiopancreatography procedures on patient doses. Radiat Prot Dosim 2016; 171: 503 - 508

[12] Lopez PO, Dauer LT, Loose R et al. ICRP Publication 139: Occupational radiological protection in interventional procedures. Ann ICRP 2018; 47: $1-118$

[13] Chida K, Kaga $Y$, Haga $Y$ et al. Occupational dose in interventional radiology procedures. AJR Am J Roentgenol 2013; 200: 138-141

[14] Zankl M. Personal dose equivalent for photons and its variation with dosimeter position. Health Phys 1999; 76: $162-170$

[15] Degiorgio S, Gerasia R, Liotta F et al. Radiation doses to operators in hepatobiliary interventional procedures. Cardiovasc Intervent Radiol 2018; $41: 772-780$

[16] Omar A, Marteinsdottir M, Kadesjo N et al. On the feasibility of utilizing active personal dosimeters worn on the chest to estimate occupational eye lens dose in x-ray angiography. J Radiol Prot 2015; 35: 271-284 [Epub 2015 Mar 18 PubMed PMID: 25785566]

\section{CORRECTION}

Roberta Gerasia, Dario Ligresti, Fabio Cipolletta et al. Endoscopist's occupational dose evaluation related to correct wearing of dosimeter during X-ray-guided procedures

Endoscopy International Open 2019; 07: E367 - E371.

DOI: $10.1055 / a-0841-3350$

In the above mentioned article was an institution missing and the corresponding address changed.

Correct is:

Roberta Gerasia ${ }^{1}$, Dario Ligresti², Fabio Cipolletta², Antonino Granata ${ }^{2}$, Ilaria Tarantino ${ }^{2}$, Luca Barresi², Michele Amata ${ }^{2}$, Sabrina Benenati ${ }^{1}$, Giuseppe Gallo ${ }^{1}$, Corrado Tafaro $^{1}$, Roberto Miraglia ${ }^{1}$, Mario Traina ${ }^{2}$

2 IRCCS-ISMETT (Istituto Mediterraneo per i Trapianti e Terapie ad alta specializzazione), Palermo, Italy - Endoscopy Service, Department of Diagnostic and Therapeutic Services, Palermo, Italy

Corresponding address

Dario Ligresti, Endoscopy Service, Department of Diagnostic and Therapeutic Services, IRCCS ISMETT UPMC, Via E. Tricomi 5 - 90127 Palermo, Italy, Phone: +390912192772, +393669142811 (mob.), Fax: +39 0912192400, dligresti@ismett.edu 